\title{
Kepemimpinan Transformasional Dan Transaksional Berdasar Nilai Ajaran Astha Brata
}

\section{Yanuar Bagas Arwansyah}

Universitas Sebelas Maret

yanuarbagasa93@gmail.com

\section{Article History}

received $1 / 9 / 2021$

\begin{abstract}
This study aims to describe the integration of the values of Astha Brata's teachings in Raden Ngabei Ranggawarsita's Serat Aji Pamasa in the transformational and transactional leadership styles of modern society. The research method uses descriptive qualitative by conducting a literature review of previous research to analyze the application of leadership and transformational styles in five institutions or companies in Indonesia. The results of the analysis are then adjusted to the eight elements contained in the teachings of Astha Brata so that qualitative data can be obtained relating to the suitability of transformational and transactional leadership styles with the values of Astha Brata teachings. The results of this study indicate that there is an integration of astha brata teachings in transformational and transactional leadership styles in various companies. The leaders of institutions or companies prioritize human values in determining the rules of working hours, wages, work targets, rewards, and punishments. In addition, in the application of transformational and transactional leadership styles a leader acts as an example and does not just provide an example. This research can be used as a reference in applying transformational and transactional leadership styles in modern society while still prioritizing the noble values of the previous leaders through the teachings of Astha Brata.
\end{abstract}

Keywords: Leadership, Transformational, Transactional, Astha Brata

\begin{abstract}
Abstrak
Penelitian ini bertujuan mendeskripsikan integrasi nilai ajaran Astha Brata dalam Serat Aji Pamasa karya Raden Ngabei Ranggawarsita dalam gaya kepemimpinan transformasional dan transaksional masyarakat modern. Metode penelitian menggunakan deskriptif kualitatif dengan melakukan kajian pustaka terhadap penelitian terdahulu untuk menganalisis penerapan gaya kepemimpinan dan transformasional pada lima institusi atau perusahaan di Indonesia. Hasil analisis kemudian disesuaikan dengan delapan unsur yang terdapat dalam ajaran Astha Brata sehingga dapat diperoleh data kualitatif berkaitan dengan kesesuaian gaya kepemimpinan transformasional dan transaksional dengan nilai ajaran Astha Brata. Hasil penelitian ini menunjukkan bahwa terdapat integrasi nilai-nilai ajaran astha brata dalam gaya kepemimpinan transformasional dan transaksional di berbagai perusahaan. Para pimpinan institusi atau perusahaan mengutamakan nilai-nilai kemanusiaan dalam menentukan aturan jam kerja, pengupahan, target kerja, reward dan punishment. Selain itu, dalam penerapan gaya kepemimpinan transformasional dan transaksional seorang pemimpin bertindak sebagai contoh dan tidak hanya memberikan contoh. Penelitian ini dapat dijadikan referensi dalam menerapkan gaya kepemimpinan transformasional dan transaksional dalam masyarakat modern dengan tetap mengedepankan nilai-nilai luhur para pemimpin terdahulu melalui ajaran Astha Brata.
\end{abstract}

Kata kunci: Kepemimpinan, Transformasional, Transaksional, Astha Brata

Social, Humanities, and Education Studies (SHEs): Conference Series https://jurnal.uns.ac.id/shes 


\section{PENDAHULUAN}

Kepemimpinan adalah kunci dalam menentukan keberhasilan sebuah pekerjaan dalam mencapai target dan keberlangsungan sebuah organisasi atau instansi. Karakter seorang pemimpin menjadi dasar dalam pengambilan keputusan yang vital dan berkelanjutan. Keberhasilan atau kegagalan sebuah kepemimpinan terletak pada kualitas karakter. Kepemimpinan yang baik dapat menentukan keberlangsungan kinerja, motivasi, ketercapaian target (Covey, 2010).

Pemimpin memiliki peranan sebagai figurehead yaitu bertugas sebagai sosok utama dalam sebuah organisasi atau institusi yang dipimpinnya dalam kepentingan formal. Seorang pemimpin memiliki peranan sebagai leader yang bertanggung jawab dalam membentuk motivasi, inovasi, dan solusi berbagai permasalahan serta menjalin hubungan interpersonal dengan bawahan. Peran lain sebagai perantara (laison manager) yang bertugas untuk melakukan interaksi dengan pihak eksternal dan internal pada organisasi atau institusi yang dipimpinnya (Bushra, Usman and Naveed, 2011). Kepemimpinan dipahami sebagai proses memengaruhi orang lain untuk melaksanakan sesuatu dengan tujuan tercapainya suatu target atau keberhasilan tertentu (Terry and Rue, 2005).

Masyarakat modern membagi kepemimpinan dengan berbagai pengertian dan gaya yang merujuk pada sistem penerapannya. Sementara itu, dalam perjalanannya terdapat berbagai gaya kepemimpinan baru yang muncul akibat dari perkembangan ilmu pengetahuan dan teknologi yang berimbas pada perkembangan pola pikir masyarakat. Hal ini tentunya menjadikan masyarakat memiliki banyak referensi baru berkaitan dengan gaya kepemimpinan yang akan digunakan sebagai acuan. Akan tetapi, munculnya berbagai gaya kepemimpinan baru di tengah masyarakat ini berbanding lurus dengan kemunculan konflik-konflik internal dan eksternal. Oleh karena itu, menjadi penting dalam menentukan gaya kepemimpinan yang diacu dengan mempertimbangkan nilai-nilai dasar yang harus dimiliki seorang pemimpin (Muhardi and Siregar, 2013).

Nilai-nilai dasar seorang pemimpin sejatinya telah muncul sejak bangsa ini masih berupa kerajaan-kerajaan yang tersebar di seluruh Indonesia. Para pemimpin kerajaan terdahulu mengajarkan nilai-nilai positif yang dapat dijadikan dasar dalam menentukan gaya kepemimpinan yang diacu. Raden Ngabei Ranggawarsita dalam Serat Aji Pamasa merumuskan Nilai Ajaran Astha Brata yang berisi nilai-nilai dasar yang harus dimiliki seorang pemimpin.

Gaya kepemimpinan transformasional dan transaksional banyak digunakan oleh pimpinan sebuah organisasi atau instansi di Indonesia. Oleh karena itu, penanaman nilai ajaran Astha Brata dalam penerapan gaya kepemimpinan tersebut menjadi dasar untuk membekali para pemimpin dan calon pemimpin agar memiliki dasar nilai dalam diri untuk membentuk karakter pemimpin yang baik.

Penelitian ini bertujuan mendeskripsikan integrasi nilai ajaran Astha Brata dalam Serat Aji Pamasa karya Raden Ngabei Ranggawarsita dalam gaya kepemimpinan transformasional dan transaksional masyarakat modern. Penerapan gaya kepemimpinan transformasional dan transaksional harus didasari nilai-nilai ajaran Astha Brata agar tidak hanya ketercapaian target yang diperoleh namun juga terjalinnya keberlangsungan hubungan baik internal dan eksternal dalam organisasi atau institusi yang dipimpin.

\section{KAJIAN TEORI}

Pemimpin Kepemimpinan transformasional adalah gaya kepemimpinan yang berlandaskan dasar bahwa jika dalam sebuah pekerjaan atau kegiatan lain di luar kebiasaan yang telah ditetapkan sebelumnya (status quo) untuk memeroleh target atau capaian baru (O'Leary, 2001). Kepemimpinan transformasional juga diartikan sebagai kegiatan memengaruhi lain untuk bekerja sama dalam mencapai tujuan yang 
diinginkan (Tead, 1985). Kepemimpinan transformasional pada praktiknya seorang pemimpin memiliki kekuatan untuk memengaruhi bawahan dengan metode tertentu. Penerapan kepemimpinan transformasional menanamkan pemikiran bahwa bawahan akan merasa dihargai, dipercaya, dan loyal kepada pimpinannya (Bass and Riggio, 2006).

Proses perubahan besar dalam sikap dan asumsi anggota organisasi dan membangun komitmen untuk misi atau tujuan organisasi (Tracey and Hinkin, 2013). Kepemimpinan transformasional memiliki indikator sebagai berikut: pembaharu, pemberi contoh, pendorong kinerja, harmonisasi lingkungan kerja, pemberdayaan bawahan, berasas sistem nilai, kontinyuitas peningkatan kemampuan, dan kemampuan situasional (Danim and Suparno, 2009).

Berdasar beberapa pendapat di atas dapat disimpulkan bahwa kepemimpinan transformasional berdasar pada istilah to transform, yang memiliki makna mentransformasilkan atau mengubah suatu hal menjadi baru atau berbeda dari sebelumnya. Penerapan gaya kepemimpinan transformasional harus mampu mentransformasikan dengan maksimal sumber daya untuk mencapai tujuan. Sumber daya di sini terdiri atas sumber daya manusia, keuangan, sarana prasarana, dan faktor eksternal.

Sementara itu, kepemimpinan transaksional adalah gaya kepemimpinan yang efisien dalam mencapai target. Salah satu bentuk penerapannya adalah dengan reward and punishment. Gaya kepemimpinan ini memastikan sumber daya memiliki kemampuan yang dibutuhkan untuk menyelesaikan pekerjaan. (Wibowo and Susilowati, 2010). Kepemimpinan transaksional cenderung menekankan pemberian penghargaan kepada bawahan dan kontrol pekerjaan bawahan.

Selain itu, pemimpin memberikan arahan pada tujuan yang telah ditetapkan untuk menjelaskan beban kerja dan target yang harus dipenuh (Garnasih and Pramadewi, 2013). Kepemimpinan transaksional merupakan gaya kepemimpinan di mana seorang pemimpin lebih cenderung memberikan arahan pada bawahannya, dan memberi insentif serta hukuman pada kinerja mereka serta menitik beratkan terhadap perilaku untuk membimbing pengikutnya (Maulizar and Yunus, 2012).

Gaya kepemimpinan transaksional juga dikenal sebagai kepemimpinan manajerial yang berfokus pada peran pengawasan, organisasi, dan kinerja kelompok. Gaya kepemimpinan transaksional adalah gaya kepemimpinan di mana pemimpin mendorong kepatuhan pengikutnya melalui dua faktor yaitu imbalan dan hukuman. Para pemimpin dengan gaya kepemimpinan transaksional bekerja dengan cara memperhatikan kerja karyawan untuk menemukan kesalahan dan penyimpangan. Jenis kepemimpinan ini sangat efektif dalam situasi krisis dan darurat.

Astha Brata merupakan nilai ajaran yang ditulis Raden Ngabei Ranggawarsita. Astha Brata berasal dari bahasa Sansekerta. Astha bermakna wolu atau delapan dan Brata bermakna tingkah laku untuk mengendalikan diri. Astha Brata memaknai nilai ajaran dalam kepemimpinan ke dalam delapan unsur yang ada di alam semesta yakni bumi, matahari, api, samudera, langit, angin, bulan, dan bintang. Dalam setiap unsur Astha Brata memaknai karakter ideal yang harus dimiliki seorang pemimpin atau calon pemimpin.

Astha Brata sejatinya adalah konsep kepemimpinan pada zaman kerajaan Hindu, tertulis dala kitab Manawa Dharma Sastra yang mana menceritakan tentang dasar acuan karakter yang harus dimiliki pemimpin pada saat itu yang sesuai dengan karakteristik para Dewa. Masuknya Islam di Indonesia menjadikan konsep Astha Brata disesuaikan dengan ajaran Islam yang monoteis sehingga ditransformasikan ke dalam delapan unsur alam. Transformasi sifat-sifat dewa menjadi delapan unsur alam sendiri tercatat dalam naskah Pustakaraja Purwa.

Nilai luhur Astha Brata terdiri atas delapan unsur alam, yaitu (1) Mahambeg Mring Bhumi (Bumi), seperti bumi, seorang pemimpin haru menjadi pribadi yang kuat, 
dapat diandalkan, dan dapat memberikan pengayoman pada bawahannya. (2) Mahambeg Mring Suryo (Matahari), pemimpin harus mampu memberikan energi berupa inspirasi, visi, dan manfaat pada setiap keputusan. (3) Mahambeg Mring Dahana (Api), api memiliki hukum yang jelas, merepresentasikan kewibawaan, keberanian, dan keyakinan kuat serta mencerminkan ketegasan dalam pengambilan keputusan. (4) Mahambeg Mring Samudro (Samudera), merepresentasikan suatu pemikiran yang luas dan tidak gegabah dalam menerima berbagai informasi dan mengambil tindakan. (5) Mahambeg Mring Angkasa (Langit), merepresentasikan keluasan batin dan pemikiran serta langit menyimbolkan keluasan kompetensi dan keterampilan yang dapat ditularkan ke orang lain. (6) Mahambeg Mring Maruto (Angin), merepresentasikan bahwa seorang pemimpin harus dapat dirasakan keberadaannya dan pengaruhnya. (7) Mahambeg Mring Condro (Bulan), seorang pemimpin harus dapat menjadi penerang dalam kegelapan, menjadi pribadi yang solutif dan inovatif dalam meyelesaikan segala permasalahan. (8) Mahambeg Mring Kartika (Bintang), merepresentasikan sifat bintang yang memancarkan cahaya indah, seorang pemimpin semestinya menjadi teladan bagi bawahannya.

\section{METODE}

Metode penelitian menggunakan deskriptif kualitatif. Deskriptif kualitatif digunakan untuk meneliti pada kondisi objek yang alamiah di mana peneliti adalah sebagai instrument kunci teknik pengumpulan data yang dilakukan dengan trigulasi (gabungan), analisis data bersifat induktif/kualitatif, dan hasil penelitian kualitatif lebih menekankan makna daripada generalisasi. Data penelitian ini diambil dengan melakukan kajian pustaka terhadap penelitian terdahulu untuk menganalisis penerapan gaya kepemimpinan dan transformasional pada lima institusi atau perusahaan di Indonesia. Hasil analisis kemudian disesuaikan dengan delapan unsur yang terdapat dalam ajaran Astha Brata sehingga dapat diperoleh data kualitatif berkaitan dengan kesesuaian gaya kepemimpinan transformasional dan transaksional dengan nilai ajaran Astha Brata (Creswell, 2013) (Moleong, 2010) (Sugiyono, 2018).

\section{HASIL DAN PEMBAHASAN}

Pemimpin Penelitian ini menganalisis hasil penelitian terdahulu tentang penerapan kepemimpinan transformasional dan transaksional di beberapa perusahaan dan institusi di Indonesia kemudian diintegrasikan dengan nilai ajaran Astha Brata. Data penelitian ini yaitu hasil penelitian terkait pengaruh penerapan gaya kepemimpinan transformasional dan transaksional di (1) Dinas Kesehatan Kota Malang, (2) PT Bangun Satya Wacana Surabaya, (3) PT Sanjayatama Lestari, (4) Kantor Pos Lumajang, (5) Sekolah Tinggi Agama Islam Negeri Jawa Timur.

Berdasarkan hasil analisis dokumen penelitian terdahulu diperoleh data bahwa kelima perusahaan dan institusi tersebut menerapkan gaya kepemimpinan transformasional dan transaksional. Penelitian yang dilakukan pada kelima penelitian terdahulu tersebut menggunakan metode eksperimen. Kelima penelitian terdahulu menganalisis berkaitan dengan pengaruh gaya kepemimpinan transformasional dan transaksional terhadap kinerja karyawan.

Hasil analisis penelitian ini kemudian dijabarkan dalam bentuk tabel untuk memperjelas data hasil analisis dokumen yang diperoleh. Berikut tabel hasil analisis dokumen terkait penerapan gaya kepemimpinan transformasional dan transaksional di kelima perusahaan dan institusi tersebut. 
Tabel 1. Hasil Analisis Dokumen

\begin{tabular}{|c|c|c|}
\hline Institusi & Transformasional & Transaksional \\
\hline $\begin{array}{l}\text { Dinas Kesehatan Kota } \\
\text { Malang }\end{array}$ & $\begin{array}{l}\text { Pemberian kepercayaan } \\
\text { pada bawahan }\end{array}$ & $\begin{array}{l}\text { Pemberian reward and } \\
\text { punishment pada karyawan }\end{array}$ \\
\hline $\begin{array}{l}\text { PT Bangun Satya } \\
\text { Wacana Surabaya }\end{array}$ & $\begin{array}{l}\text { Pemberian pelatihan } \\
\text { pada bawahan tentang } \\
\text { teknis sesuai bidang } \\
\text { masing-masing }\end{array}$ & $\begin{array}{l}\text { Pemberian arahan dalam } \\
\text { penerapan SOP dan } \\
\text { pembuatan petunjuk } \\
\text { penyelesaian target secara } \\
\text { efisien }\end{array}$ \\
\hline $\begin{array}{l}\text { PT Sanjayatama } \\
\text { Lestari }\end{array}$ & $\begin{array}{l}\text { Pemberian contoh } \\
\text { kedisiplinan dan } \\
\text { pemimpin menunjukkan } \\
\text { sikap solutif dan inovatif } \\
\text { dalam penyelesaian } \\
\text { masalah }\end{array}$ & $\begin{array}{l}\text { Pemberian penghargaan dan } \\
\text { memberikan penjelasan beban } \\
\text { kerja }\end{array}$ \\
\hline Kantor Pos Lumajang & $\begin{array}{l}\text { Pemberian contoh } \\
\text { disiplin dan Teknik } \\
\text { pencapaian target }\end{array}$ & $\begin{array}{l}\text { Pemberian reward and } \\
\text { punishment pada karyawan, } \\
\text { pemberian penjelasan target } \\
\text { kerja }\end{array}$ \\
\hline $\begin{array}{l}\text { Sekolah Tinggi } \\
\text { Agama Islam Negeri } \\
\text { Jawa Timur }\end{array}$ & $\begin{array}{l}\text { Pemberian stimulasi } \\
\text { intelektualitas, Pemimpin } \\
\text { menunjukkan sikap } \\
\text { karismatik, pemberian } \\
\text { inspirasi, pemberian } \\
\text { pertimbangan individual }\end{array}$ & $\begin{array}{l}\text { Penghargaan dan pengecualian } \\
\text { perlakuan }\end{array}$ \\
\hline
\end{tabular}

Berdasarkan hasil analisis dokumen di atas dapat dilihat bahwa seluruh perusahaan dan instansi di atas melaksanakan gaya kepemimpinan transformasional dan transaksional. Hasil analisis di atas akan diintegrasikan dengan nilai ajaran Astha Brata sebagai berikut.

1. Dinas Kesehatan Kota Malang

Penerapan gaya kepemimpinan di Dinas Kesehatan Kota Malang berdasar hasil analisis di atas menunjukkan bahwa pemimpin menggunakan gaya kepemimpinan transformasional dengan memberikan kepercayaan pada bawahan, hal ini sesuai dengan nilai Mahambeg Mring Bhumi (Bumi) yang ditunjukkan dengan mengayomi bawahan melalui pemberian kesempatan dan kepercayaan pada bawahan untuk melakukan tugas dengan sebaik-baiknya. Hal ini menjadi penting karena kepercayaan yang diberikan kepada bawahan membuat mereka merasa dihargai dan dipercaya kemampuannya. Selain itu, pemimpin juga menggunakan gaya kepemimpinan transaksional yang berlandaskan nilai ajaran Mahambeg Mring Dahana (Api) dengan memberikan reward dan punishment yang bertujuan untuk memberikan penghargaan pada bawahan yang bekerja dengan baik dan sesuai target, serta memberikan hukuman bagi karyawan yang tidak bekerja sesuai SOP dan tidak memenuhi target. Hal ini ditujukan demi memegang teguh asas keadilan.

2. PT Bangun Satya Wacana Surabaya

Penerapan gaya kepemimpinan di PT Bangun Satya Wacana Surabaya berdasar hasil analisis di atas menunjukkan bahwa pemimpin menggunakan gaya kepemimpinan transformasional dengan pemberian pelatihan pada bawahan tentang teknis sesuai bidang masing-masing dengan tujuan meningkatkan kemampuan karyawan atau bawahannya agar terus berkembang. Hal ini sesuai dengan nilai Mahambeg Mring Bhumi (Bumi) yang ditunjukkan dengan memberikan 
ilmu yang bermanfaat bagi karyawannya. Selain itu, kegiatan ini juga merupakan bentuk Mahambeg Mring Maruto (Angin) yang berarti keberadaan pemimpin dapat dirasakan bawahannya dan menunjukkan bahwa pemimpin peduli terhadap bawahannya atau karyawannya. Sementara itu, gaya kepemimpinan transaksional ditunjukkan dengan pemberian arahan dalam penerapan SOP dan pembuatan petunjuk penyelesaian target secara efisien. Hal ini sesuai dengan nilai Mahambeg Mring Kartika (Bintang) yang mana pemimpin harus dapat menjadi teladan bagi bawahannya.

3. PT Sanjayatama Lestari

Penerapan gaya kepemimpinan di PT Sanjayatama Lestari berdasar hasil analisis di atas menunjukkan bahwa pemimpin menggunakan gaya kepemimpinan transformasional dengan pemberian contoh kedisiplinan dan pemimpin menunjukkan sikap solutif dan inovatif dalam penyelesaian masalah. Hal ini sesuai dengan nilai ajaran Astha Brata yaitu Mahambeg Mring Condro (Bulan) dan Mahambeg Mring Kartika (Bintang).

Sementara itu, gaya kepemimpinan transaksional ditunjukkan dengan pemberian penghargaan dan memberikan penjelasan beban kerja. Hal ini mencerminkan nilai ajaran Mahambeg Mring Dahana (Api) dan Mahambeg Mring Angkasa (Langit).

4. Kantor Pos Lumajang

Penerapan gaya kepemimpinan di Kantor Pos Lumajang berdasar hasil analisis di atas menunjukkan bahwa pemimpin menggunakan gaya kepemimpinan transformasional dengan pemberian contoh disiplin dan teknik pencapaian target. Hal ini sesuai dengan nilai ajaran Astha Brata yaitu Mahambeg Mring Kartika (Bintang) yang ditunjukkan dengan pimpinan yang mampu menjadi contoh atau panutan bagi bawahannya. Selain itu, ditunjukkan pula dengan nilai Mahambeg Mring Condro (Bulan) yang direpresentasikan dengan seorang pemimpin yang mampu memberikan solusi dalam setiap permasalahan.

Sementara itu gaya kepemimpinan transaksional ditunjukkan dengan pemberian reward and punishment pada karyawan, pemberian penjelasan target kerja. Hal ini mencerminkan nilai ajaran Mahambeg Mring Dahana (Api) dan Mahambeg Mring Angkasa (Langit) yang mana ditunjukkan dengan ketegasan pemimpin dala memberikan penghargaan dan sanksi sesuai dengan kinerja karyawan.

5. Sekolah Tinggi Agama Islam Negeri Jawa Timur

Penerapan gaya kepemimpinan di Kantor Pos Lumajang berdasar hasil analisis di atas menunjukkan bahwa pemimpin menggunakan gaya kepemimpinan transformasional dengan pemberian stimulasi intelektualitas, pemimpin menunjukkan sikap karismatik, pemberian inspirasi, pemberian pertimbangan individual. Hal ini sesuai dengan ajaran Mahambeg Mring Suryo (Matahari), Mahambeg Mring Condro (Bulan), dan Mahambeg Mring Kartika (Bintang).

Sementara itu gaya kepemimpinan transaksional ditunjukkan dengan penghargaan dan pengecualian perlakuan. Hal ini sesuai dengan ajaran Mahambeg Mring Samudro (Samudera) ditunjukkan dengan pemberian perlakuan yang tidak gegabah dan disesuaikan dengan kondisi karyawan.

\section{SIMPULAN}

Berdasarkan hasil analisis di atas dapat disimpulkan bahwa terdapat integrasi nilai-nilai ajaran Astha Brata dalam gaya kepemimpinan transformasional dan transaksional di berbagai perusahaan. Para pimpinan institusi atau perusahaan mengutamakan nilai-nilai kemanusiaan dalam menentukan aturan jam kerja, pengupahan, target kerja, reward, dan punishment. Selain itu, dalam penerapan gaya 
kepemimpinan transformasional dan transaksional seorang pemimpin bertindak sebagai contoh dan tidak hanya memberikan contoh.

Penelitian ini dapat dijadikan referensi dalam menerapkan gaya kepemimpinan transformasional dan transaksional dalam masyarakat modern dengan tetap mengedepankan nilai-nilai luhur para pemimpin terdahulu melalui ajaran Astha Brata. Astha Brata merupakan satu dari filosofi kepemimpinan paling kompleks yang ada saat ini. Tidak hanya kompleks, Astha Brata dengan membawa filosofi Jawa membawa beberapa kelebihan sebagai satu konsep kepemimpinan. Dengan semua sifat di atas, pemimpin dengan delapan karakteristik Astha Brata merupakan membawa ciri kepemimpinan paling ideal.

\section{DAFTAR PUSTAKA}

Bass, Bernard M., and Ronald E. Riggio. (2006). Transformational Leadership. New Jersey: Lawrence Erlbaum Associates Publishers.

Bushra, Fatimah, Ahmad Usman, and Asvir Naveed. (2011). "“Effect of Transformational Leadership on Employees" Job Satisfaction and Organizational Commitment in Banking Sector of Lahore (Pakistan)." International Journal of Business and Social Science, 12 (18).

Covey, Stephen R. (2010). Pinciple Centered Leadership. London: Simon \& Sschuster Inc.

Creswell, W. J. (2013). Research Design. Yogyakarta: Pustaka Pelajar.

Danim, Sudarwan, and Suparno. (2009). Manajemen dan Kepemimpinan Transformasional Kekepalasekolahan. Jakarta: Rineka Cipta.

Garnasih, R. L., and A. Pramadewi. 2013. "Kepemimpinan Transformasional Dan Kepemimpinan Transaksional Serta Pengaruhnya Terhadap Kinerja Dosen Fakultas Ekonomi Universitas Riau", Jurnal Ekonomi, 66-76.

Maulizar, Musnadi S., and M. Yunus. 2012. "Pengaruh Kepemimpinan Transaksional dan Transformasional Terhadap Kinerja Karyawan Bank Syariah Mandiri Cabang Banda." Jurnal Manajemen Pascasarjana Universitas Syiah Kuala, 58-65.

Moleong, J. L. 2010. Metodologi Penelitian Kualitatif. Bandung: Remaja Rosdakarya.

Muhardi, and M. R. Siregar. 2013. "Pengaruh Kepemimpinan Transformasional dan Transaksional Terhadap Kinerja Pegawai Badan Investasi dan Promosi Aceh." Jurnal Ekonomi Manajemen dan Bisnis, 1(11), 99-117.

O'Leary, Elizabeth. 2001. Kepemimpinan: Menguasai Keahlian yang Anda Perlukan dalam 10 Menit. Yogyakarta: Deddy.

Sugiyono. 2018. Metode Penelitian Kuantitatif, Kualitatif, dan R\&D. Bandung: Alfabeta.

Tead, Ordway. 1985. The Art of Leadership. Whittlesey House: McGraw-Hill Book Company.

Terry, George R., and Leslie W. Rue. 2005. Dasar-dasar Manajemen penerjemah: G.A. Ticoalu. Jakarta: Bumi Aksara.

Tracey, J. B., and T. R. Hinkin. 2013. "Transformasional leadership or effective management practices." Group and Organization Management, 220-236.

Wibowo, Edi, and Wiwik Susilowati. 2010. "Pengaruh Kepemimpinan, Organizational Citizenship Behaviour, dan Komitmen Organisasional terhadap Kepuasan Kerja Pegawai." Jurnal Ekonomi dan Kewirausahaan, 66-73. 